\title{
La Estructura de "Piedra de Sol"
}

Los dos polos opuestos a que tiende la poesía de Paz, lo personal y lo universal, se hacen más evidentes en "Piedra de Sol", nombre con que se designa a la maciza piedra del calendario azteca, y título del largo poema que bien puede ser la obra maestra del poeta. Precede al poema un epígrafe, los cuatro primeros versos del "Artemis" de Gerardo de Nerval, y le sigue una nota aclaratoria del poeta en la cual da una clave explícita, cosa única en su obra hasta la fecha, para la interpretación del poema, su relación con los ciclos del calendario precolombino. Precisamente, lo que sustenta a la obra es la oposición entre el epígrafe y la nota, los cuales, aunque ajenos a la forma de la poesía, son parte integrante del tema de la misma, el tiempo.

"Artemis", dentro de la producción relativamente limitada de Nerval, es una de sus composiciones mejor conocidas y al mismo tiempo está entre las poesías más enigmáticas de este desconcertante precursor del Simbolismo y del Surrealismo. El número de interpretaciones que se han dado de "Artemis" comprueban el hecho de su importancia para el lector contemporáneo. No se puede afirmar con absoluta seguridad que se haya expuesto un juicio definitivo de esta oscura mezcla de mitología, cristianismo y símbolos personales, pues es lógico pensar que habrá en el futuro opiniones y teorías opuestas sobre cuál es su verdadero sentido. Quizás la interpretación crítica vaya precisamente contra $1_{a}$ intención del autor, pues el mismo Nerval fue el primero en advertir que la esencia de su poesía podría perderse si se la lograba explicar.

Hasta ahora la primera estrofa ha sido la mejor aclarada de todo el poema.

La treizième revient... c'est encore la première;

et c'est toujours la seule - ou c'est le seul moment; car es-tu reine, ô toi, la première ou dernière?

es-tu roi, toi le seul ou le dernier amant? 
En ella, indudablemente, la asociación más esencial es la del número trece con el tiempo. Nerval mismo aclaró esto, no solamente en el sub. título de uno de sus manuscritos, "Ballet des heures" sino también en una nota al margen de otro: "La XIIle heure (pivotale)."1 Sin embargo una poesía clave de un autor tan influyente en Baudelaire y Mallarmé ha de tener más de una interpretación.

Varios intérpretes han tratado de encontratle un significado al número trece en la vida de Nerval. Por ejemplo, el lapso de tiempo transcurrido después de su primer ataque de locura, o el aniversario de la muerte de Sophie Dawes. Ninguno de estos hechos se opone a la hipótesis de que Nerval compusiera el poema el primer día del año 1854 (lo que vendría a ser el mes y la hora trece).$^{2}$ Los biógrafos de Nerval han recalcado la profunda convicción que él tenía en que las estrellas regian su destino, y el detallado estudio de Richer atestigua la confianza del poeta en los números, cábalas y símbolos ocultos. Sin embargo nada de lo anterior contradice el que el símbolo del trece se identifique fundamentalmente con el tiempo; por el contrario, otras explicaciones más bien amplían y refuerzan esa interpretación.

El número trece, además de su connotación tradicional de mala suerte, significa en particular la muerte en la baraja "tarot". ${ }^{3}$ El trece no solamente es la hora de la muerte, sino también está asociado a la luna en general y a los trece meses lunares en particular. Una lámina de Isis en Oedipus Aegyptiacus (1652) de Athanasius Kircher, una de las fuentes principales de Nerval, parece tener una conexión directa con el soneto de este poeta:

Ce chiffre de treize noms peut se rapporter au vers initial d'Artémis: ... La treizième c'est la Lune dans cette liste et le nom de Diane. Artémis (titre du sonnet de Nerval) constitue le pivot: il est précedé de six noms et suivi de six autres. Des correspondances aussi curieuses ne peuvent être dues au simple hasard. ${ }^{4}$

La luna también puede ser vista como un símbolo que abarca la antinomia que existe entre principio y fin, o vida y muerte. La brillantez de la luna mata, opacando, a las estrellas: 'L'Occident est l'Etre ou le

1 Nerval, Chimères, ed. Moulin, 54-55.

2 Constans, "Sophie, Aurelia, Artémis," Mercure, 312, 270; Richer, Doctrines esotériques, 114.

3 Onimus, "Artémis," Mercure, 324, 74.

4 Richer, Doctrines, 119 y 128. 
Temps que tue (occidere), puis qu'il fait disparaître le Soleil et tous les astres." 5

Cuando Paz escribió "Piedra de Sol" es posible que desconociera la concreta relación entre el tiempo y "Artemis", y que sólo tuviera presente los distintos símbolos en cuanto a la luna. De todos modos, su significado revestía un carácter tan personal para Nerval que no se puede esperar que pueda penetrar su hermetismo el moderno lector no especializado. Jean Ominus comenta acertadamente que su explicación "décevra par sa simplicité les amateurs de symbolisme". Al parecer el título de Nerval recuerda la viva impresión que le causó un reloj de péndulo estilo renacimiento muy trabajado, en el cual la figura del tiempo estaba sostenida por carátides:

La Diane historique, accoudée à son cerf, est en basrelief sous le cadran où s'étalent sur un fond niellé les chiffres émaillés des heures ... Les anciens cadrans portent au-dessus des chiffres 1 , 2 , 3, etc., les numéros 13,14, 15, etc. L'éternelle ronde des heures, manifester la sérénité du divin, en contraste avec cette figure du Temps qui dominait l'édifice. La précision des détails monte a quel point Nerval en 1853, dix-huit ans plus tard, garde l'exacte mémoire d'un objet qu'il a longuement contemplé et qui, sans doute, l'a fait rêver. Diane devient ainsi pour lui le symbole même du Temps. ${ }^{6}$

En su origen, al menos, la relación de Diana-Artemis con el tiempo es tan personal para Nerval como muy concreta su identificación con el reloj. Para Paz su importancia obviamente está no en la asociación mitológica sino en el concepto cíclico del tiempo, el cual Ominus expresa con la ecuación $1=13 .{ }^{7}$ En "Piedra" continuamente se insinúa este sentido cíclico del tiempo mediante el uso de la coma y los dos puntos como substituto del punto. El signo de dos puntos o de punto y coma se usa conjuntamente con el hemistiquio para indicar gráficamente en nueve momentos la combinación de interrupción y continuidad.

Además del tema del tiempo, hay otros dos aspectos de "Artemis" que contribuyen a la comprensión de "Piedra de Sol". Richer ha expli-

5 Ibid., 117-118.

6 Onimus, "Artémis," 76.

7 En su libro Les métamorphoses du cercle (Paris, Plon, 1961), Georges Poulet describe la tradición larga del círculo en la literatura, y dedica todo un capítulo a Nerval. Es interesante notar que el único escritor de habla española que merece tantan atención en el libro es Jorge Guillén. 
cado los trece nombres de Isis, lo cual es importante no sólo por ser equivalentes al número de horas para Nerval, sino también porque señala la múltiple identidad de la diosa. Otro crítico ha indicado que detrás de Artemis se esconde la persona de Isis y se pregunta si Nerval no estaría invirtiendo el proceso, ya que Isis al aparecérsele a uno de sus adoradores le mostraba la cara de su amada, mientras que Nerval busca a la diosa en la cara de varias mujeres. ${ }^{8}$ Richer utiliza dos citas de "Aurelia" para demostrar convincentemente que para Nerval, Isis se convierte en la Virgen y en una figura madre y en Venus: "Tris est dite déesse polymorphe, déesse aux mille noms." " La misma multiplicidad de símbolos se aplica en "Piedra" a la diosa del tiempo, la que se invoca especialmente hacia el final del poema.

Otra relación que se ve entre el epígrafe y "Piedra" es el uso de las palabras "première", "dernière y "seul", las cuales normalmente son términos que expresan oposición, pero que aquí al contrario se usan como sinónimos. El juego de contrastes se desarrolla extensamente en las cuartetas de "Artemis"; en realidad, solamente ocho versos carecen de términos que contrastan claramente, y en los versos finales del soneto se halla el mayor contraste de todos que abarca y explica al resto. Igualmente, el uso de paradojas, tanto en el tema como en la metáfora, es uno de los rasgos característicos de "Piedra".

La nota que puso el poeta a la primera edición de "Piedra" (1957) da una orientación totalmente diferente al poema. Sin embargo dicha nota, breve pero reveladora, se omitió en la colección definitiva Libertad bajo palabra, y cabe preguntarse la razón de esta omisión. ¿Creería Paz que revelaba demasiado? ¿Tendería la nota a deformar la reacción del público lector ante una obra tan importante?

La presente nota demuestra la importancia del jeroglífico maya en la cubierta traduciendo su significado como 585, y añade que símbolos pictóricos indicando el principio y el fin corresponden respectivamente al Día 4 Olin (Movimiento) y al Día 4 Ehécatl (Viento). El número de endecasílabos 584 ( $\sin$ contar los versos 585.90 que repiten los seis primeros del poema) corresponde al ciclo sinódico de Venus. Como Venus aparece tanto por la mañana como por la noche, los hombres han convertido esa dualidad en símbolo de la esencial ambigüedad del universo. Asimismo Ehécatl era una de las formas de Quetzalcóatl, la serpiente emplumada que representa las dos caras de la vida. Venus para el mundo occidental era una compleja asociación de imágenes y de fuerzas ambiguas a las que se refiere el poeta.

${ }^{8}$ Constans, "Artémis," Revue de litterature comparée, 14, 362.

- Richer, Doctrines, 126-127. 
A pesar de la oposición entre el epígrafe y la nota del poeta, existe entre ambas un elemento numérico en común, el número trece, que es a la vez el símbolo del tiempo cíclico para Nerval y el número de meses en el cómputo lunar del calendario azteca (260 días divididos en trece meses de veinte días cada uno, a los cuales se añadían 105 días del cómputo solar para completar el año). De esta manera también hay una conexión entre los trece meses lunares del año solar en el calendario europeo y el cómputo del calendario azteca. Por tanto, los cálculos matemáticos del tiempo lunar refuerzan sutilmente, pero sin dejar lugar a dudas, el simbolo de la luna según lo entiende Nerval en el preámbulo del poema. El número trece tiene otras funciones en el calendario azteca. Por ejemplo, la semana constaba de trece días y un "siglo" de 52 años lo formaban cuatro grupos de trece años cada uno. Por otra parte, cada uno de estos grupos quedaba bajo la influencia de uno de los cuatro puntos cardinales.

En el punto medio entre el epigrafe y la nota aclaratoria del poeta sobre el calendario azteca está el elemento estructural más importante del poema, el verso o mejor dicho la designación poética "Madrid, 1937". A primera vista éste parece señalar un simple cambio de asunto y tono. Sin embargo, el lector presiente que hay algo más, que dicho título quizás se refiera a una de las experiencias más profundas en la vida del poeta independientemente del poema. Paz confirma la importancia filosófica de esta experiencia en un párrafo autobiográfico de El laberinto de la soledad:

Recuerdo que en España, durante la guerra, tuve la revelación de "otro hombre" y de otra clase de soledad: ni cerrada ni maquinal, sino abierta a la trascendencia. ${ }^{10}$

Paz sabe que muchas de las aspiraciones españolas se frustraron, pero el recuerdo de ese ideal se ha hecho parte de su carácter, de su destino, de sus aspiraciones:

Pero su recuerdo no me abandona. Quien ha visto la Esperanza, no la olvida. La busca bajo todos los cielos y entre todos los hombres. Y sueña que un día va a encontrarla de nuevo, no sabe dónde, acaso entre los suyos. En cada hombre late la posibilidad de ser, o más exactamente, de volver a ser, otro hombre. ${ }^{11}$

10 México, 1959, p. 25.

11 Ibid. Ia frase en letra bastardilla es de Paz. 
Obviamente el título "Madrid, 1937" se puede interpretar como una experiencia existencial que dividió la vida del poeta en dos.

La estructura del poema refleja cuán trascendental fue la experiencia vivida. El lugar que ocupa "Madrid, 1937" en el poema es prominente, ya que situado entre los versos 287 y 288, sólo dista cinco líneas del mismo centro. $\mathrm{Y}$ aunque hubiera sido un perfecto endecasílabo si la fecha se hubiera deletreado, llamaría la atención no sólo por ser un verso que el poeta no cuenta en el total de 584, sino también porque es una obvia intrusión poco musical en el ritmo circular. $\mathrm{La}$ intromisión produce un choque, el que es intensificado por el hecho de no haber usado el poeta un punto para indicar el fin de la primera parte antes de introducir el cambio inesperado; por el contrario, sólo emplea comas tal como lo hace a través del poema. El título indicando lugar y fecha es, paradójicamente, un corte que a su vez no lo es.

En forma similar el lector puede hacer una comparación y contraste entre las dos mitades del poema. Ambos tratan de hallar cuál es el sentido de la vida, ambos comprenden, tal como hemos de ver, la repetición de una experiencia esencial, aunque las experiencias de cada parte son de naturaleza opuesta; ambos describen el carácter cíclico del tiempo. En términos generales el asunto de las dos partes es el mismo, pero no lo son el sentido y el tono, pues en ellos hay una oposición fundamental. Recordemos que el epígrafe sugiere un análisis metafísico del número trece como primero, último, a su vez lo mismo, y estático dentro del tiempo. Al plantear específicamente mediante dos preguntas las implicaciones de primero o último, conjuntamente con el tema de la identidad (rey o reina), Nerval ha empezado una serie de preguntas en las que unas se suceden a las otras y que cada vez se hacen más íntimas. Al lector se le lleva a reaccionat subjetivamente y a dudar, tal como lo ha hecho el poeta, del tiempo y de la realidad. La primera mitad de "Piedra" sigue por lo general el mismo camino interior. El poeta bucea dentro de su alma en un ir hacia lo profundo de su propia identidad mientras lucha por definir la realidad primaria.

La primera parte del poema gira alrededor del epígrafe así como la segunda tiende a seguir la dirección de la nota aclaratoria del poeta. La oposición entre el epígrafe y la nota se basa en los conocimientos adquiridos de ésta, pues al combinar ciencia y mito se depende no de elucubraciones propias, sino de lo que se ha logrado colectivamente y de fenómenos comprobables. Se orienta por tanto hacia lo exterior. La segunda mitad del poema, manteniendo esta orientación, describe la realidad en términos sociales más bien que individuales: guerra, amor, aspira- 
ciones humanas y problemas sociales. Mientras el tono de la primera parte es hermético, el tono dominante de la segunda es abierto. Si se aprovechan frases del propio Paz usadas en otro sentido más amplio, podemos decir que la primera mitad es "poesía de la soledad" y que la segunda es "poesía de la comunión".

Esta distinción no necesariamente indica que cada parte es un todo unido que se opone a la otra. Por el contrario, veremos que lo opuesto es verdad; el poeta ha planeado y llevado a cabo intrusiones de la primera parte en la segunda y de ésta en aquélla. La diferente orientación de cada una debe verse en términos de la tendencia dominante, la cual intencionalmente incluye ejemplos de la tendencia contraria.

Aunque el tema de "Piedra" es la relación entre tiempo y realidad, la variedad de significados de los términos relacionados con el tiempo es escasa. Tienden a lo concreto las palabras "minuto", "hora" o especialmente "instante" que utiliza Paz, y quedan para un simbolismo más amplio las otras facetas del poema. Inclusive el concepto tiempo, que generalmente es abstracto, se limita a una situación particular, con la excepción importante de los versos 189-199, o a una reacción personal y pasajera más que a una profunda especulación filosófica. Es más, en el empleo de las palabras relacionadas con el tiempo tara vez se encuentra una clara justificación de la idea de lo circular, que tanto el título como la estructura del poema simbolizan.

Un análisis de las distintas referencias al tiempo produce categorías comunes y permite tres clasificaciones generales: tiempo normal o de uso corriente, tiempo medido por la experiencia del poeta, y ausencia de tiempo como característica de la eternidad. La decoración del paisaje surrealista que sirve de introducción $(15-16,21,31$, etc.) incluye referencias al tiempo que son fácilmente comprensibles en un contexto normal. Aunque estas referencias llaman la atención en la primera parte del poema, como si el poeta hubiera querido establecer una amplia base de mutuo entendimiento acerca del concepto del tiempo, sobre la cual construir su precario andamiaje de impresiones personales y conceptos filosóficos, también ocurren en otras partes:

mientras afuera el tiempo se desboca (159)

el mundo con su horario carnicero (161)

mientras el tiempo cierra su abanico (171)

presente sin ventanas (225)

pétalo de cristal es cada hora (401)

silencio: cruzó un ángel este instante (436) 
Aún cerca del final, después de haberse desarrollado completamente numerosos temas secundarios y símbolos, puede verse que por un breve intervalo el tiempo reaparece usado de una manera común y corriente: "se despeñó el instante en otro y otro" (572).

El concepto que tiene el poeta del tiempo como producto de su propia experiencia anticipa la estructura circular del poema. En una de las invocaciones a su amada, que tiene muchos nombres y caras, el verso del poeta se asemeja directamente al del epígrafe: "tienes todos los rostros y ninguno, / eres todas las horas y ninguna" (116-117). Esta idea será ampliada usando expresiones que unen lo cíclico del tiempo con lo concreto, la cara de la amada, y de ahí con lo pasajero, ya que el tiempo todo lo cambia:
rostro de llamas, rostro devorado, adolescente rostro perseguido años fantasmas, días circulares que dan al mismo patio, al mismo muro atde el instante y son un solo rostro los sucesivos rostros de la llama, todos los nombres son un solo nombre, todos los rostros son un solo rostro, todos los siglos son un solo instante y por todos los siglos de los siglos cierra el paso al futuro un par de ojos, (142-152)

En el comentario más significativo sobre su experiencia del tiempo, el poeta destaca lo que tiene de cíclico mediante el empleo del presente progresivo, que tiene la virtud de transformar el concepto lineal del tiempo, que es el más común, en la paradójica unión del pasado con el presente:

oh vida por vivir y ya vivida, tiempo que vuelve en una marejada

y se retira sin volver el rostro, lo que pasó no fue pero está siendo y silenciosamente desemboca en otro instante que se desvanece: (189-194)

A lo largo del poema hay otras señales de que la vuelta del tiempo es un dilema y un símbolo de la desorientación del poeta. Bien porque el 
presente carezca de sentido al prolongarse interminablemente, bien porque los sucesos personales o los históricos carezcan de importancia al repetirse sin cesar, la reacción del poeta al retorno del tiempo se sintetiza en el verso 49.8, "cada minuto es nada para siempre." Los primeros versos de la última estrofa expresan su conclusión íntima sobre el dilema del tiempo:

quiero seguir, ir más allá, y no puedo:

se despeñó el instante en otro y otro (571.572)

Frente al concepto normal y corriente del tiempo, es decir, concepción lineal del mismo formado por unidades medidas que se extienden hacia adelante y hacia atrás, se alza el concepto predominante en el poeta de la vuelta del tiempo, anunciado ya en el epígrafe. Sin embargo el conocimiento de que un instante es a la vez primero, último y único no le trae tranquilidad, paz ni satisfacción. Por el contrario, darse cuenta de esto implica para el poeta que existe una realidad primaria, un paraje sin tiempo al que busca por encima de toda otra realidad, y el cual se entrevé en varias experiencias amorosas de la segunda mitad. El poco espacio dedicado a la idea de un paraíso no sujeto al tiempo está en razón inversa a su importancia, pero el hecho de su colocación hacia la conclusión del poema no deja duda en cuanto a que es la meta sentimental. Por encima de toda descripción, ese objetivo mantiene la más firme esperanza de una plena satisfacción personal y social.

Fuera de la excepción antes indicada, las referencias obvias al tiempo no lo desarrollan suficientemente como tema, pero sirven para corroborar más bien la propia impresión del lector sobre su fugacidad y naturaleza incierta, además de lo difícil que es llegar a una conclusión satisfactoria. Lo que aporta el poema a una más amplia definición, relacionando el tiempo a la realidad, no se logra mediante palabras que sugieren ideas o conceptos relativos al tiempo, sino por el modelo, y especialmente por la repetición, de la experiencia del poeta. Antes de examinar ésta, debemos observar el efecto logrado por los cuatro puntos cardinales, pues su empleo permite decir que esta experiencia tiene validez universal.

Los conceptos del tiempo y del espacio en la cosmología azteca se funden, lo que es bien distinto del desarrollo completamente independiente que han seguido en la Europa occidental:

Enfin, de même qu'il n'y a pas un espace mais des espaces, il n'y a pas un temp mais des temps. De plus, chaque espace est lié à un 
temps, ou à des temps. Ainsi la mentalité mexicaine ne connaît pas l'espace et le temps abstraits, mais des sites et des événements. Les propriétés de chaque espace sont aussi celles du temps qui lui est attaché, et réciproquement. Tout phénomène du monde ou de la vie humaine prend place en un lieu et en un moment déterminés; sa tonalité, sa valeur émotionelle, les prévisions qu'on en peut tirer pour l'avenir, dépendent de ce complexe singulier d'espace et de temps où il est apparru. ${ }^{12}$

El ciclo de 52 años del calendario azteca siempre empieza con 1 acatl, el año del Este, lo que indica no sólo el principio del mundo, sino tam. bién el nacimiento del sol y el dominio de Quetzalcóatl, el cual después de su sacrificio reapareció en el Este como la estrella de la mañana. ${ }^{13}$ Luego el Este simboliza renacimiento, resurrección:

C'est donc par excellence la région de la jeunesse, du jeune maïs, des jeunes dieux de la végétation, toujours peints et vêtus de rouge, du chant, des fêtes, de l'aurore. Pour les anciens Mexicains, toutes ces images s'identifiaient avec une réalité géographique: la côte du Golfe, la terre chau de l'est, «au bord de la mer divine, de l'eau celeste», selon l'expression des Anales de Cuauhtitlán. ${ }^{14}$

Por tanto es lógico suponer que la primera sección de "Piedra" refleje las cualidades del Este, y de hecho esto se logra de distintas maneras. La geografía de la escena es obviamente paradisíaca. El desarrollo complejo de la imagen árbol-agua (versos 1-3) y la ambigüedad en su identificación, es decir, si el objeto es átbol, fuente o ambas cosas a la misma vez, hacen pensar en un paisaje ideal, a lo que contribuye el río eterno (4-6). El fluir acompasado y atemporal del agua produce una sensación de armonía, especialmente en "unánime presencia en oleaje", y se logra el máximo de intensidad en la línea 12 y en el símil magnífico de abrir las alas en mitad del cielo.

El paisaje que se sugiere en la estrofa siguiente es obviamente el de un bosque primitivo, con imágenes que refuerzan nuevamente los elementos de la naturaleza: "espesuras", "ave petrificando el bosque con el canto", y la felicidad, desapareciendo entre el ramaje, como si fuera una fruta de la que comen los pájaros. Las siguientes cinco estrofas constituyen un himno de alabanzas a la amada del poeta (23.75) en el cual

12 Soustelle, Actualités scientifiques, 58.

13 Ibid., 85.

14 Ibid., 59. 
las características físicas son convertidas en abstracciones ("cuerpo de luz filtrada por un ágata", "tu vientre es una playa soleada", "eres una ciudad que el mar asedia"), llegando finalmente a identificársele con una diosa de la lluvia ("tu falda de maíz ondula y canta", "toda la noche llueves, toda el día / abres mi pecho con tus dedos de agua"). En la última estrofa de este primer himno el poeta vaga a través de una geografía verdadera que él ha creado de las abstracciones, y vuelve luego mediante símiles del río y del bosque al primer paisaje que evocó. Juventud, crecimiento, origen, amanecer, vegetación y agua: todos son cląros atributos del Este con el que se identifica el principio del poema.

En la estrofa que comienza con el verso 67 se inicia un nuevo asunto tras una transición en que se continúan las alabanzas del cuerpo de la amada (67 y 68 recuerdan a los versos 41 "voy por tu cuerpo", 53 "voy por tus ojos", y 56 "voy por tu frente"), acompañada de otra serie paralela de imágenes de la naturaleza. Pero ahora por primera vez ésta se convierte en peligrosa "como por un sendero en la montaña / que en un abismo brusco se termina", y la sombra del poetà, de hecho su propia identidad, se hace añicos y él trata en vano de recobrar los fragmentos.

Las dos próximas estrofas insisten en un motivo que va aumentando en importancia a medida que reaparece, el de la completa dispersión de la personalidad del poeta. Todo lo que él ve y toca, todo su yo, se desintegra completamente. En esta sección se llega al primer punto culminante mediante la negación del tiempo, recordando el acertijo del epigrafe y descubriendo la conexión entre el mismo y el hecho de que el poeta está consciente de su falta de identidad:

piso días, instantes caminados, piso los pensamientos de mi sombra, piso mi sobra en busca de un instante, (95-97)

Sigue el poeta buscando la realidad en los versos 98 y 99 pero esta vez las asociaciones son más agradables, apropiadas a la salida de la escuela de unas niñas. A pesar del marcado cambio en el tono y en el asunto, continúa todavía el tiempo siendo el tema de la nueva estrofa. $\mathrm{La}$ aparición de las niñas sugiere el empezar de la vida, el nacer, especialmente por el hecho de que ellas salen de "su entraña tosada". Una niña a quien provisionalmente no se le ha dado nombre es el objeto de una letanía en la larga estrofa que sigue, versos 109-141. La alabanza a esta niña es, más que a su belleza o a su divinidad, una serie de epítetos a veces paradójicos, los cuales tienen en común referirse a lo que 
hay de sobrenatural en la vida. De hecho, ella es un muestrario de maravillas, y lo que se infiere es que es una síntesis de todas mujeres:

adolescente rostro innumerable, he olvidado tu nombre, Melusina, Laura, Isabel, Perséfona, María, tienes todos los rostros y ninguno, eres todas las horas $\mathrm{y}$ ninguna, te pareces al árbol y a la nube, eres todos los pájaros y un astro, te pareces al filo de la espada

y a la copa de sangre del verdugo, yedra que avanza, envuelve y desarraiga al alma y la divide de sí misma, escritura de fuego sobre el jade, grieta en la roca, reina de serpientes, (113-125)

El contraste entre los versos anteriores y la primera parte reside en parte en la distinta geografía que se contempla. Así como el espíritu del Este fue el predominante en la introducción, ahora el punto cardinal opuesto en la cosmología azteca es el que va a influir en el tratamiento de la materia. Al Oeste se le conocía como Cuiatlampa, el lugar de las mujeres y la morada de diosas y semi-diosas. ${ }^{15}$ Tanto era esto así que los indios mexicanos precolombinos le rezaban al Oeste pidiendo un buen parto. El poeta ha escogido conscientemente la imagen que sugiere el nacer en el trozo anterior y aún mejor la de la niña sin nombre, que representa a todas las mujeres (incluyendo a Melusina y a Perséfone) con el fin de impulsar su tema hacia otro punto del calendario de piedra. Este trozo termina como el del Este, con una vuelta al nombre sin nombre, a la cara sin cara y al momento ajeno al tiempo (146-152). El vacío en la transición que precedió a este trozo es semejante a la transición al siguiente, el cual todavía tiene que ver con el tiempo, aunque sea negándolo:

no hay nada frente a mi, sólo un instante (153)

Después de haber desarrollado el tema del renacer identificado con el Este y de lo femenino identificado con el Oeste, el lector lógicamente busca indicaciones del Norte y del Sur, pero éstas no son tan evidentes

15 Ibid., 62. 
de hallar. La tazón puede que esté en la mitología azteca, la cual aunque había producido cierto número de leyendas y creencias sobre estos dos puntos cardinales, carecía sin embargo de la claridad, precisión y unidad que caracteriza a los otros dos puntos, íntimamente relacionados con la diaria aparición y desaparición de la divinidad más importante. Es posible por ello que el poeta no le encontrara asociaciones ya establecidas al Norte y al Sur que hubietan podido usarse en el poema, pero tam. bién es probable que deseara evitar un tratamiento rígido de la cosmología azteca.

El desarrollo en la primera parte de la mitología azteca relacionada con los cuatro puntos cardinales es una manera sutil pero efectiva de establecer un enlace entre las dos mitades, pues en realidad es una ampliación de la nota aclaratoria del poeta. La mitología azteca, pudiera sostenerse con razón que encaja mejor en la segunda parte, pero lo que debe advertirse es que esta mitología no es tanto asunto como ambiente, telón que sirve de fondo al desarrollo del tema. Esta sutil introducción de la segunda mitad no está nada fuera de lugar, pues el poeta con gran cuidado ha logrado a veces anticipar y otras recordar indirectamente lo ya tratado.

La ausencia del Norte y del Sur la compensa el otro de los puntos cardinales precolombinos, el centro sobre el que descansa todo el sentido del poema. En la cosmología azteca el centro tiene un significado simbólico del que carece el de la decorativa rosa náutica de la cosmografía europea:

... Cest le lieu de croisement des autres directions, le lieu de rencontre du haut et du bas. Les particularités des espaces s'y totalisent. . .

... Tantôt le centre est considéré comme la synthèse des autres espaces, participant de leurs qualités diverses, et comme le lieu stable, où repose le foyer divin de Xiubtecutli, prototype et source de tous les foyers; tantôt il n'est plus que le lieu inquiétant des apparitions et des présages, le point de rencontre de mondes étrangers. Il présente un aspect favorable et un aspect néfaste, un aspect «droit» et un aspect «gauche»..$^{16}$

Además de la línea "Madrid, 1937", que ya ha sido indicada como el centro matemático del poema, hay otro centro que adquiere importancia por su repetición periódica. "Madrid, 1937" es realmente una línea

16 Ibid., 67. 
divisoria tanto en el poema como en la vida del poeta. El otro centro que llamaremos simbólico se hace patente por la intencional ambigüedad de la expresión "Cest toujours la seule", que ahora se puede aplicar a la repetición de la misma experiencia varias veces en cada mitad, o mejor dicho, a la constante repetición bajo dos formas de una sola experiencia.

Este centro simbólico de la primera mitad está precedido por la desintegración de la facultad de percibir el mundo real e incluye la desmembración surrealista del mismo poeta. Dicho centro se caracteriza por la disminución del estado consciente del poeta a su nivel más sencillo, que es la conciencia de su propio esfuerzo por comprender. Representa el primero de tres puntos culminantes de la primera mitad en que se revela la experiencia más profunda:

$$
\begin{aligned}
& \text { y a la salida de tu blanca frente } \\
& \text { mi sombra despeñada se destroza, } \\
& \text { recojo mis fragmentos uno a uno } \\
& \text { y prosigo sin cuerpo, busco a tientas, (72.75) }
\end{aligned}
$$

La eliminación progresiva de la realidad objetiva es un intento, aunque por vía negativa, de definir la esencia de la vida, es en la primera mitad el primero de tres momentos en que se trasciende, en que el poeta va más allá de sí mismo a una nueva percepción. Estos tres momentos considerados en conjunto pueden designarse como la construcción por medio de la destrucción.

Es significativo que la primera desintegración esté situada precisamente entre los trozos que simbolizan al Este y al Oeste, respectivamente. La experiencia poética que precede al primer trascender en el verso 75 adquiere el carácter de una aventura, la cual el uso reiterado de "voy" recalca, obvio no sólo al comienzo de las estrofas, versos 34 y 41 , y dos veces en lo más culminante de los versos 67 y 68, sino también repetido enfáticamente dentro de las estrofas, versos 37.53 .56 y 58, siempre al principio de verso. Aunque no tan enfático como "voy", el uso de "busco" siempre también al comienzo de verso $(85,90,98$, 99) indica la continuación de la aventura entre el trascender primero y el segundo, una aventura descrita ahora en términos temporales: "busco una fecha viva como un pájaro, / busco el sol de las cinco de la tarde" (98-99). Entre el segundo momento trascendental y el tercero una digresión sobre el tiempo interrumpe la búsqueda (171-188). Ésta se presenta dramáticamente, ya que el poeta primero es conducido y luego destruido por una figura femenina, lo que desemboca en el nihilismo trascendental. 
Con el verso 98 se reafirma la meta mediante términos positivos. El tiempo queda a un lado, desaparece entre abstractas cualidades femeninas, y todo culmina en una larga serie de paradojas muy rebuscadas hasta que se llega al segundo momento trascendental en la estrofa que inicia el verso 142. Aquí, a la mitad de la primera mitad, cuarta parte de todo el poema, hay un punto culminante en el desarrollo del tema del tiempo al fundirse su aspecto positivo, el fin perseguido, con el negativo, la imposibilidad de alcanzarlo: todo el tiempo es un instante, si sólo el poeta pudiera hallarlo, apresarlo y expresarlo. (La vitalidad del presente se expresa en éste como en otros poemas mediante el uso de "arder" (146) que simboliza no la destrucción, sino la esencia de la vida).

La sección dedicada al Oeste, que esencialmente es un catálogo de los atributos maravillosos y a veces paradójicos que caracteriza tanto a una feminidad divina como a una divinidad femenina, termina con una breve pero profunda reflexión sobre el aspecto cíclico del tiempo, recalcado por la repetición paralela, especialmente en los versos 148-150, lo que lleva nuevamente a la conciencia existencial de si mismo: "no hay nada frente a mí, sólo un instante" (153).

El pesimismo, nihilismo y desolada auto-conciencia de la estrofa que comienza con el verso 153 tiene un carácter único, y sin embargo reproduce exactamente el tono de la estrofa iniciada con el verso 90. Toda la fuerza de la estrofa le viene precisamente de ser una reafirmación, así que su carácter único, otra paradoja, proviene de ser una repetición. La segunda experiencia poética se enriquece por la primera y ésta, si se relee a su vez, se enriquece al anticipar la segunda. De esta forma el carácter cíclico del tiempo queda revelado mediante lo experimentado por el poeta, por lo que dice sobre la experiencia y por lo que el poema implica acerca de ambos como un absoluto.

Una vez más la desintegración física (165-170) acompaña al conocimiento del carácter cíclico del tiempo y otra vez el poeta pasa al más allá en una estrofa que es una transición mágica tanto en la forma como por el tema. De nuevo es el tiempo el denominador común pero ahora el tema es alegre y las imágenes en verdad son fecundas, no nihilistas. En un encadenamiento surrealista el instante resulta ser semilla y fruta madura que se hace árbol, el cual al mismo tiempo es el poeta. Por tanto, cuando se invoca al tiempo cíclico al final del trozo, una actitud positiva o al menos objetiva toma el lugar de la previa amargura:

lo que pasó no fue pero está siendo

y silenciosamente desemboca en otro instante que se desvanece: (192-194) 
El carácter cíclico del tiempo reaparece después de la interrupción de la estrofa 194.95 y sus cualidades destructivas se desarrollan más ampliamente. Ahora la mujer desconocida a quien se dirige (¿será la misma?) parece que representa características opuestas a la visión sensual del verso 41 :

ardo sin consumirme, busco el agua y en tus ojos no hay agua, son de piedra, $\mathrm{y}$ tus pechos, tu vientre, tus caderas son de piedra, tu boca sabe a polvo, tu boca sabe a tiempo emponzoñado, tu cuerpo sabe a pozo sin salida, (200-205)

Antes lo había rescatado del poder del tiempo, pero ahora es un instrumento de castigo del tiempo. Por ella viene la desintegración que es el último punto culminante de la primera mitad del poema:

y tus palabras afiladas cavan mi pecho y me despueblan y vacían, uno a uno me arrancas los recuerdos, he olvidado mi nombre, mis amigos gruñen entre los cerdos o se pudren comidos por el sol en un barranco, (217.222)

Resulta otra vez que la única realidad que se puede expresar es la conciencia del poeta de su propia conciencia:

$$
\begin{aligned}
& \text { conciencia traspasada por un ojo } \\
& \text { que se mira mirarse hasta anegarse } \\
& \text { de claridad: }(228-230)
\end{aligned}
$$

Después de cada desintegración el poeta comienza de nuevo o, mejor aún, el poema sigue su curso. Este recomenzar se inicia en cada caso con la causa directa de la desintegración. En la primera la búsqueda, en la segunda el propio tiempo, y en la tercera la abstracción de la mujer. Repetido aproximadamente cada 75 versos, el paralelismo que existe entre las tres situaciones queda reforzado y su repetición intensifica el carácter cíclico del ticmpo, tema del poema.

Los últimos treinta versos de la primera mitad anticipan las características principales de la segunda parte por las referencias autobiográfi- 
cas, las reminiscencias concretas y la falta de hermetismo. Sin embargo, son presentadas en una sección que termina con preguntas sobre la iden. tidad (260-61) y a la que sigue una confusión caótica de términos usados para ilustrar precisamente dichas preguntas (282-87). En realidad representan un eslabón que une la segunda mitad, una ampliación al inquirir filosófico sobre la naturaleza del tiempo. El nihilismo de cada trascender en los puntos culminantes niega lo que se expone, así que las preguntas, aunque parecen las mismas, tienen un efecto de acumulación, intensificación y profundidad. Cada referencia a lo cíclico sirve como recordatorio al lector de los previos puntos culminantes. Étos son, tanto en sentido literal como figurado, "instantes caminados". La conclusión de la primera parte sugiere que la búsqueda del poeta ha sido infructuosa porque sigue prisionero de su conciencia, que es el único medio que tiene para vencer al tiempo.

En la segunda mitad la dirección de la experiencia poética es más bien exterior que interior. Domina ahora la experiencia amorosa y no se trata del "yo" aislado, sino que el "tú y yo" es lo esencial. En esta parte el amor es un místico acercarse a la vida y se convierte en su objetivo; por tanto, el tono es optimista a diferencia de la primera mitad. Se contraponen a los tres puntos culminantes de la primera parte los cuatro de la segunda. Lo que ambas mitades tienen en común es que vuelve a ocurrir el trascender o al menos el intento de trascender el tiempo y la realidad. Esta aparición a intervalos fijos del centro simbólico es lo que da unidad a la estructura del poema.

El efecto del cambio en la segunda parte del poema hubiera sido muy intenso con sólo haberse cambiado su ambiente, trasladándolo al mundo exterior $y$ tomando como tema principal a la sociedad en vez de la psicología personal. Sin embargo, el cambio se destaca más por la violencia del bombardeo de Madrid, durante el cual una pareja busca paz y seguridad en el amor. Bien por medio de la expresión "vuelven al principio", o la subjetividad de la exclamación "oh ser total", o la transición hábilmente lograda de la descripción en tercera persona a la participación expresada por el uso de la primera persona del plural en los versos 295 297 , el proceso de integración que se sugiere es diametralmente opuesto al de la previa desintegración del poeta:

los dos se desnudaron y se amaron por defender nuestra porción eterna, nuestra ración de tiempo y paraíso, tocar nuestra taíz y recobrarnos, 
recobrar nuestra herencia arrebatada

por ladrones de vida hace mil siglos,

los dos se desnudaron y besaron

porque las desnudeces enlazadas

saltan el tiempo y son invulnerables,

nada las toca, vuelven al principio,

no hay tú ni yo, mañana, ayer ni nombres

verdad de dos en sólo un cuerpo y alma,

oh ser total. . (295-307)

La próxima estrofa parece que deja de ocuparse de los amantes para dirigir una visión más amplia a toda la sociedad, tal como puede verse en varias habitaciones $e$ individuos, los que al fin son generalizados mediante una serie de abstracciones discontinuas, y éstas a su vez son transformadas en espacios (321-328). Como en todos los momentos culminantes del poema, el tiempo interviene en la transformación, pero ahora éste, tiempo lineal, es vencido por el amor:

no hay tiempo ya, ni muro: ¡espacio, espacio, abre la mano, coge esta riqueza, corta los frutos, come de la vida, tiéndete al pie del árbol, bebe el agua!, (330-333)

Es cierto que el amor sólo está implicito en estos versos, pero tiene su origen en la unión atemporal, el paraíso recobrado del verso 305 . Es más, la declaración del tiempo del amor se reafirma explícitamente en los primeros versos de la siguiente estrofa:

todo se transfigura y es sagrado, es el centro del mundo cada cuarto, es la primera noche, el primer día, el mundo nace cuando dos se besan, (334.337)

Sin transición ahora, el punto central enfocado es nuevamente la sociedad, presentando una galería de tipos y profesiones caricaturescos. Hay de hecho, en cuanto a la materia no trascendente, una progresión que va de lo concreto a lo general, de lo descriptivo a cada vez más lo abstracto. Después del muestrario de cosas desagradables, que ocupa veinte versos referidos a un solo verbo final, "se derrumban", es el amor en el tercer momento trascendental de esta segunda mitad el que proporciona la visión de paz, unidad y plena satisfacción en la vida: 


\begin{abstract}
se derrumban
por un instante inmenso y vislumbramos

nuestra unidad perdida, el desamparo

que es ser hombres, la gloria que es ser hombres

y compartit el pan, el sol, la muerte,

el olvidado asombro de estar vivos; (359-364)
\end{abstract}

La idea anterior se desarrolla en los versos $365-376$ y queda sintetizada en los últimos versos de esta parte: "el mundo cambia / si dos se miran y se reconocen, / amar es desnudarse de los nombres:"

Existe un paralelismo entre la serie de imágenes de lo feo que a continuación aparece y el contraste que se da entre los mundos real e ideal de los versos 340-360. El poeta da una lista de pecados, selección de crímenes contra el orden social (suicidio, incesto, asesinato, adulterio, sodomía), que son preferibles al tedio del tiempo común y corriente. Por repugnantes que sean, cualquier cosa es mejor que la monotonía, vacío y esclavitud del tiempo lineal calificado como "mierda abstracta".

Después de una breve, enigmática e inesperada visión de Dios, que no ha sido lograda por medio del amor, el poeta reanuda su búsqueda. La novedad de la estrofa que empieza con el verso 408 la constituye una vuelta a los elementos de la primera mitad del poema: "sigo mi des-

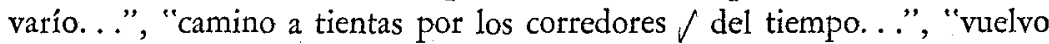
adonde empecé...", "camino por las calles de mí mismo...". Pero un "tú" femenino destruye la soledad y una vez más la tensión se resuelve mediante la feliz unión de los amantes, la abolición del tiempo, la realidad primaria sin nombres y la verdadera percepción del tiempo, "tiempo total donde no pasa nada / sino su propio transcurrir dichoso," (424-434).

Si uno repasa las escenas de éxtasis que detienen al tiempo para el poeta y que dan una nueva dimensión a la realidad, se nota que hay cierta regularidad: $301-310,329-337,359-380$ y $424-434$; como se ve, las tres primeras secciones distan unos 30 versos entre sí, y esta separación se duplica, 60 versos, entre la tercera y la cuarta. Esta regularidad es paralela a la que existen en la primera parte, según antes se señaló, pues en aquélla hay tres puntos culminantes, al ocurrir los tres intentos de trascender, distantes unos de otros 75 versos aproximadamente: 75-97, 152-170, 217-230. Esas tres experiencias de lo trascendente tienen un propósito parecido - la aniquilación de la identidad- pero son diametralmente opuestos en su forma de ser. La de la primera mitad caracterizadas por el epígrafe de "Artemis" miran hacia adentro, explorando y 
destilando la experiencia de la soledad en el tiempo hasta que no queda nada sino la conciencia de la conciencia. Las de la segunda mitad, bajo la benévola influencia de Venus, alcanzan la victoria sobre el tiempo a través del amor. Verdaderamente éstas son las dos caras de una misma moneda. En ambas partes la región sin tiempo es la médula del poema y a ella siempre regresa con regularidad el tema. Recordemos que en el calendario azteca el centro es el quinto punto cardinal, y por tanto en el poema toma lugar preeminente sobre los otros.

El largo trozo que comprende los versos 435.487 no es otra cosa que una disertación sobre la historia, que termina con una serie de preguntas sobre el sentido de la misma. Las respuestas, en particular del verso 490 ("no hay redención, no vuelve atrás el tiempo"), son una monótona y deliberada repetición que trae a la memoria la primera mitad ya recordada en los versos 392-394. La idea dominante de esta estrofa es el verso 498: "cada minuto es nada para siempre".

El hecho de que la búsqueda filosófica del poeta ha terminado en un callejón sin salida es indicado por el abandono del tratamiento directo del tiempo en la última parte del poema. Sin embargo, transfiere su angustia a un asunto parecido, al sentido de la vida en general y al lugar que ocupa el individuo en ella. La invocación a Eloísa, Perséfone y María (historia, mitología y cristianismo) para que revelen su verdadera identidad y así el poeta conozca la suya, anticipa la oración final que comien. za con el verso 533 .

La oración, dirigida al parecer a una divinidad precolombina, es la parte más conmovedora de la obra por su tono apremiante. La angustia del rezo surge de la esperanza de que el poeta (y la humanidad) sea liberado de los estrechos límites del tiempo. La oración es acogida favora. blemente y el poeta entra en un paraíso construido a base de difíciles $y$ oscuras inágenes relacionadas con el agua y que se hallan en los últimos seis versos del poema. Con la descripción del ría que es a su vez origen y término, el poema concluye muy característica y atrevidamente con un adverbio y dos puntos, los que son una promesa de eternidad: "y llega siempre:".

El lector recuerda que sin embargo éste es el mismo verso con que se inició el poema. La verdadera conclusión pudiera ser el verso 584 ("y su magia de espejos revivía"), el que insinúa por el uso que hace el poeta del espejo las cualidades ilusorias de la vida. Sin embargo, desde el punto de vista gramatical, el verso 584 no puede ser la conclusión, porque los objetos del verbo se encuentran en el próximo verso, y por tanto, el lector está obligado a continuar con los versos siguientes, los que son a la vez conclusión e introducción. 
El que termine el ciclo del poema con el verso 584, el recorrido sinódico de Venus, sirve para recordar la conexión que existe con la es. tructura del calendario. En especial uno debe tener presente los últimos días del año solar, los que no encajan en las unidades periódicas y que sin embargo han de tenerse en cuenta, pues han de transcurrir antes de que comience el nuevo año. Quizás porque su sistema en otros aspectos era tan simétrico e intrincado, los aztecas le tenían terror a estos días sobrantes, llamados nemontemi, o sea los días sin nombre, o desgraciados. Aunque no es necesario considerar los cinco versos del 585 al 590 nefastos, bien pudieran serlo; de cualquier manera, su empleo dramático fuera de la cuenta perfecta de los versos permite establecer un paralelo con los nemontemi.

El temor a que el mundo se acabara no se limitaba a los nemonáemi. Se hace obvio igualmente tanto en cada día como en las eras, los dos extremos del calendario. La trayectoria del sol no era para los indios algo inalterable, sino que por el contrario se le consideraba como algo milagroso que requería la cooperación de los hombres. El sol se sustentaba de la sangre, preferentemente humana, vertida en los sacrificios. Otra gran inseguridad existía al final de una era, pues entonces el destino no ya del mundo, sino del universo estaba en la balanza. En la mitología azteca el mundo había sido destruido cuatro veces y recreado otras tantas. Toda la cosmología azteca, por lo tanto, era no solamente cíclica sino frágil, pues en cualquier momento podía detenerse el movimiento circular. El momento de empezar o de terminar como aquí en el poema, era visto primero con pavor, y luego con júbilo que culminaba en la glorificación de aquellas fuerzas que causan la renovación.

Aunque todo el calendario azteca está compuesto de ciclos interdependientes, la divinidad a quien se confiaba principalmente el proceso de la renovación era Quetzalcóatl, quizás el más reciente, más joven y más importante de los dioses en cuanto a su popularidad. Los templos dedicados a él eran siempre circulares. Su signo en el calendario eran 4 Ehécatl (viento) y se lo representaba frecuentemente con una más cara de Ehécatl cuyos templos también eran redondos. En la mano Quetzalcóatl llevaba la joya del viento, una concha redondeada con cinco seg. mentos.

El uso de mitos aztecas hacia el final del poema para expresar la destrucción y la renovación se funde muy apropiadamente con la intención del epígrafe, y sugiere que los dos, como las dos mitades sujetas a la influencia de cada uno, son independientes pero idénticos. La primera mitad analiza el tiempo y la realidad mediante un proceso de 
desintegración; la segunda tiende al mismo fin, pero a través de un pro. ceso opuesto de integración y síntesis. Estos son, por tanto, las dos caras de la misma realidad. La conclusión que se aplica a ambos, es que el sentido que se pueda entrever, bien sea negativo o positivo, ha de dedu. cirse del proceso cíclico.

El segundo efecto importante que resulta de fundir la conclusión con el principio del poema es insinuar, o mejor dicho imponer, la necesidad de varias lecturas e interpretaciones. De la misma manera que los momentos culminantes en cada mitad eran diferentes, pero el efecto de cada uno aumentaba el del siguiente, así cada lectura se enriquece con Ia anterior. Varias lecturas permitirán ver que el proceso de desintegración de la primera mitad se contrapone a la síntesis tan creativa, social y optimista de la segunda mitad, y que ésta a su vez sólo puede interpretarse como un preludio a la inevitable destrucción y nihilismo tan patente y bien logrado de la primera mitad. Es más, la estructura circular lleva a la pérdida del sentido de la dirección. ¿Cuál es la primera mitad? El poema adquiere un tono bien diferente si las mitades se intercambian. En verdad, la división en mitades no necesariamente ha de indicar el lugar apropiado para comenzar. El efecto principal que debe producir el carácter circular es que el poema, si dejamos de lado al epígrafe, puede empezarse por cualquier verso. De esta forma Paz sometió a la máxima prueba en cuanto a la estructura el método que más tarde aplicaría conjuntamente con técnicas más complicadas a Discos visualles y a Blanco, en los cuales amplió la interpretación múltiple a través del uso de temas "modulares" en el último y la inclusión del azar en el primero.

JOHN M. FEIN

\section{Duke University}

